This is the final pre-publication version of an article submitted to Africa Education Review. The full version of this article is available at http://www.tandfonline.com/doi/abs/10.1080/18146627.2015.1036548\#.VfBG9U1RHmg

Published details:

Tassew Woldehanna and Adiam Hagos (2015) 'Economic Shocks and Children's Drop-out from Primary School: Implications for Education Policy in Ethiopia', African Education Review 12.1: 28-4

\title{
Economic shocks and children's dropout from primary school: Implications for education policy in Ethiopia
}

Tassew Woldehanna and Adiam Hagos

\begin{abstract}
This paper investigates the impact of idiosyncratic and covariate economic shocks, on the likelihood of children dropping out of primary school. In this endeavour, an Accelerated Failure Time Hazard model was estimated using data from the Young Lives study of childhood poverty. The estimated results indicate that both idiosyncratic shocks and covariate shocks have a statistically significant effect on the risk of children dropping out of primary school. Considering the fact that both idiosyncratic and area-wide economic shocks are experienced at the household level, the study concludes that it is vital to link social protection programmes to education policy as well so as to reduce the vulnerability of households to the shocks and keep children from dropping out from school.
\end{abstract}

Key words: Primary education, completion, dropout, economic shocks, Young Lives Study

\section{Tassew Woldehanna}

Associate Professor, Department of Economics, Addis Ababa University and Principal Investigator, Young Lives, Ethiopian Development Research Institute (EDRI), PO Box 2479, Addis Ababa, Ethiopia, Email - tassew.woldehanna@gmail.com (Corresponding Author) 


\section{Adiam Hagos}

Assistant Researcher, Young Lives, Ethiopia, Ethiopian Development Research Institute (EDRI), PO Box 2479, Addis Ababa, Ethiopia, Email - adiam.h19@gmail.com

\section{Introduction}

Families in Ethiopia are subject to a variety of covariate and idiosyncratic economic shocks mainly the illness of family members, and in rural areas, drought (MOFED 2008). The sources of these shocks are many, as are the ways in which they are mitigated. It is, therefore, important to know what types of shocks have a debilitating effect on a household's accumulation of human capital as children's completion of schooling is one of the vital indicators of social and economic development and the $2^{\text {nd }}$ MDG target of completing full cycle primary schooling for boys and girls (United Nations 2011). This paper discusses the incidence and intensity of idiosyncratic and covariate economic shocks and explores their impact on primary school drop-out rates, given the increased burden of work on children.

We observe that the net enrolment rate in primary education increased from 83 per cent in 2007/8 to 85.3.0 per cent in 2010/11 (MOE 2011). However, the country's ability to achieve the targets of completing full cycle primary education also depends on its ability to keep children in school. The target set by the Ethiopian Government for drop-out rates of children from primary school was 8 per cent for the year 2010/11. The actual drop-out rate in this same year, however, was 13 per cent, but the difference in rates between boys and girls was almost zero.

In Ethiopia, primary education has duration of 8 years and is composed of first cycle primary (grades 1-4, and second cycle primary (grades 5-8) educations (MoE 2012). A student is promoted from grade 8 to grade 9 when a student completes primary education, that is, when students pass grade exam provided nationally. Education is provided for free in public schools and any child has the right to enter public primary education for free. However, children have to pay out of pocket for buying education materials and school uniforms, which are unfordable for many poor children. Whenever families face economic shocks that have negative repercussions on children enrolled in school, there is no social program or formal organisations to support the children in school . 
Given the absence or lack of a more comprehensive social protection programme, economic shocks may result in the deterioration of physical, human and social capital, which can cause households to fall into a poverty trap in the situation where they do not possess enough resources to mitigate the effect of these shocks. Consequently, children may be forced to drop out of school or may be unable to attend classes regularly because of the need to either cover for labour requirements at home or to generate the additional or alternative income required to mitigate the effects of the shock. Children may also be forced to leave school because t may be too expensive for households to cover for the indirect costs of their education resulting from the economic shocks.

A few studies have explored the effect of economic shocks on children's education in Ethiopia. Admassu (2011) found that the presence of sick adult in the household reduced the likelihood of children attending school. The same was found to be true for maternal or paternal death. Likewise, children who experienced drought and food insecurity were less likely to be enrolled in primary school. Asadullah, Chaudhury and Christiaensen (2006) found that in the event of a harvest failure, girls were less likely to complete primary school while it had no significant effect on boys. Crop damage on half of a household's plot also had a negative effect on the enrolment of school-age children. To our knowledge, there is no systemic empirical study that looks the effect of economic shocks on primary completion rate taking the censored nature of the data encountered in most empirical studies of completion rate or drop out of children from primary education

The main objective of the paper is, therefore, to analyse the impact of economic shocks on primary school drop-out rates indicated by drought, crop failure and pest infestation, the death of livestock and the death or illness of members of a household.

The remaining part of the article is organized as follows. Section 2 discusses the theoretical framework followed by the methods used. The results are discussed in Section 4 ensued with the concluding remarks and recommendations made in Section 5. 


\section{Theoretical framework and empirical models}

The decision of parents to take children out of school is triggered by a number of factors. The rule parents follow when deciding to continue sending their children to school is that the benefits of attending school, in general, and future productivity gain in particular, must outweigh both the direct costs of sending a child to school and the opportunity cost of the child's time (Glewwe and Jacoby 1994 ).

In a perfect capital market, household economic characteristics would not affect a household's decision to send children to school as there would be no economic motive to delay the investment as long as it was worthwhile, i.e., if the choice between life cycle consumption and human capital investment was made independently of each other. Moreover, children's school attendance would not be affected by the need for child labour as parents could borrow to finance their consumption instead of relying on their children's earnings. The decision to take children out of school under this case, therefore, is based on the fact that the marginal rate of return to schooling equals the interest rate (Glewwe and Jacoby 1994).

However, in developing countries like Ethiopia, perfect capital markets do not exist. Household economic factors, as a result, affect a household's decision to send a child to school. Household economic variables may have an effect on educational investments by affecting the ability to buy goods that support learning when credit constraints are binding (Brown and Park 2002).

Different variables that represent the characteristics of the household may affect households' decision to send a child to school. The educational level of parents may affect the child's optimal level of education by increasing the returns to the child's education. Moreover, the returns of schooling may differ depending on the gender of the child, as a result of labour market conditions, differential treatment in school or different support for educational attainment at home (Glewwe et al. 1995).

Household's experience of economic shocks may have a long term-effect on its accumulation of productive assets, one of which is educated children (Sun and Yao 2010). In addition, different factors (variables) have been identified in different empirical studies as having an effect on the 
probability of children dropping out of school. The relationship of those variables with primary school drop-out rates in these studies is discussed below.

Sun and Yao (2010), Brown and Park (2002), Dureyea (1998) and Handa and Simler (2000) found that the educational level of parents affects the probability of parents sending their children to school. Hunter and May (2002), Woldehanna et al (2005a), Lincove (2009), Bjorkman (2005) and Brown and Park (2002) found that the gender of the child affects the probability of a child going to school. Woldehanna et al (2005) and Brown and Park (2002) found that the number of household members in a given age group affect the probability of a child staying in school. Glick et al. (2011) and Bratti and Mendola (2011) found that the probability of children dropping out of school increased with deterioration of parental health. Glick et al. (2011) and Gingoux and Mendez (2011) found that parental death increases the probability of children dropping out of school.

Krutikova (2010) and Gingoux and Mendez (2011) found that crop shocks, natural disaster and market shocks negatively affect children's educational attainment. Bjorkman (2005) showed that girls were affected more than boys by rainfall shocks, at all grades. Similarly, Brown and Park (2001) found that the drop-out rates for girls relative to boys were higher in the first three years of schooling. Gunnarson (2004) found that the effect of child labour on test scores was negative.

Theoretically and empirically, one can argue that economic shocks that have negative effect on child education can be tackled by establishing social protection programs that can prevent households from distress selling of their assets. This could be done by introducing a cash transfer program conditional on children's attendance at school. A good model for this is Progresa, which is a conditional cash transfer programme operating in Mexico. De Janvry et al. (2006) investigated whether children whose families are recipients of conditional transfers are insulated from the impacts of shocks on school enrolment and work. The results of the study showed that conditional cash transfer programmes contributed positively to the protection of children's enrolment in school, which indicates that conditional cash transfer programmes can act as safety nets that enable poor children to attend school. 
In Ethiopia there is a social assistance program known as Productive Safety Net Program (PSNP) that provides unconditional support to rural households as a response to covariate shocks such drought, crop failure and outbreak of pests and diseases. However, this assistance program does not provide support for households who suffer from death and illness of household members (Taffere and Woldehanna, 2013). Hence households who suffer from illness and death of members do not have any option to cope up with this kind of economic shocks. Therefore, theoretically one can hypostasize that if illness and death of household members are affecting children primary education completion, one solution could be linking the already exiting social protection program with the education program so as to support children who parents are suffering from illness and death.

Taking the theoretical arguments and empirical evidence into account, a model is built to identify the determinants of primary school drop-out. The child's characteristics such as gender and attendance at preschool are included, along with household characteristics such as age group and gender of the other children, educational level of parents (proxy by whether the father is literate or not ${ }^{1}$ ) of father and gender of the head of the household, to see how they affect primary school drop-out. The wealth index was also included to control for its effect on school drop-out, as it affects households' investment in human capital under the conditions where there aren't perfect capital markets.

Moreover, the model tries to capture the effect of the opportunity cost of schooling to the household by incorporating the number of hours the child spends on domestic activities (household chores and caring for younger siblings), unpaid activities (e.g. cattle herding for their own household) and paid labour.

Most importantly, idiosyncratic and covariate economic shocks were incorporated to explore their effect on children's risk of dropping out of primary school. The death or illness of household members, the death of livestock and household's experience of drought, crop failure and pest infestation are the economic shock variables taken account of. The lagged values of

\footnotetext{
${ }^{1}$ We use literacy of father instead of mother's education because the majority of the mothers are not educated and no variation in mother's education.
} 
these variables were also incorporated in the model to see whether such shocks had long-term effects.

Accordingly, the following model is adopted to identify the determinants of primary school dropout:

$D_{i t}=\beta_{0}+\beta_{1} C_{i t}+\beta_{2} H_{i t}+\beta_{3} W_{i t}+\beta_{4} O_{i t}+\beta_{5} S_{i t}+\beta_{6} S_{i t-1}+\beta_{7} U_{i t}+e_{i t}$

where $\mathrm{D}$ is the drop-out of children from school, $\mathrm{C}$ is a vector of child characteristic variables, $\mathrm{H}$ is a vector of household characteristics, $\mathrm{W}$ is wealth index, $\mathrm{O}$ is the vector of variables that represent the opportunity cost of sending children to school, $\mathrm{S}$ is the vector of dummy variables for experience of economic shock, $U$ is the dummy variable for households being located in urban areas, $\mathrm{A}$ is school start age and e represents the error term. The subscript $\mathrm{i}$ represents the observations under consideration while $\mathrm{t}$ represents the survey round.

Equation (1) suffers from censoring because when a child drops from school, we have clear information that the child does not complete primary education, but when a child is enrolled in particular grade, we do not know whether the child will drop from school after some years or not, in which in this particular it censored.By estimating equation (1) taking the censored nature of data, this paper tries to see if economic shocks are associated with children primary education completion or drop out controlling for other factors such as household and child characteristics and opportunity cost of sending children to school.

\section{Data Set and Estimation Methods}

This study utilised Young Lives Study's longitudinal survey data set gathered from Ethiopia. Young Lives Study follows 3000 children of which 1000 of them were born in 1994 (and called them Older cohort) and 2000 of them were born between 2000 and 2001 (and called them Younger Cohort). This paper specifically used the Older Cohort data from the survey undertaken by Young Lives in Ethiopia, in which the same children are followed over the course of the study. The children were 12 years old in Round 2 (2006) and 15 years old in Round 3 (2009). 
This study did not utilise data from the Younger Cohort because they were only 5 years old in Round 2 and 8 years old in Round 3 and many of them may not have been enrolled.

The older cohort sample contains 970 children, who live in 20 sentinel sites located in five of the regions in the country, namely Addis Ababa, Oromia, Amhara, SNNPR and Tigray. These regions were selected because 96 per cent of the population of the country lives there. The selection criteria adopted to choose the sentinel sites was that they had to be located in poor areas based on the country's food insecurity designations. Seventy-five per cent of the sentinel sites in each region were selected from high food deficit woredas (districts) while 25 per cent were selected from a lower food deficit woreda. The children in rural areas comprise 60 per cent of the sample while 40 per cent are from urban areas. Each region comprised 20 per cent of the total sample, except for Addis Ababa which contained 15 per cent of the sample and SNNPR from which 25 per cent of the sample was selected.

The selection of sentinel sites within regions was made based on data on population density and prevalence of critical food deficits (dependence on food aid). Moreover, consultations were made with regional policymakers and other stakeholders to guide the selection of sentinel sites. Within each sentinel site, a simple random sample of 100 households was taken.

Different models were adopted to estimate and analyse the model of children's drop-out from school specified in equation (1). One of these is a censored ordered probit model devised by Lillard and King (discussed in Glewwe 1999; Holmes 2003; World Bank 2004) to identify the determinants of school completion. However, the use of censored ordered probit models to analyse school attainment assumes that a child currently enrolled will achieve at least the grade level in which the child is currently enrolled. This is too restrictive an assumption, especially in a situation where there is a significant drop-out rate. An alternative is to use a Cox proportional hazard model to analyse school attainment or drop-out (Cox and Oakes 1984). Hazard models account for the dependence of current enrolment on past enrolment decisions, and handle censored students (i.e. children enrolled at the time of the survey). 
The Cox hazard model does not require a parametric specification of the baseline hazard function and thus allows the baseline hazard rate for each community to vary (Cox and Oakes 1984; Brown and Park 2002). However, the use of this model requires that the variables under consideration must pass a proportionality test (Bhattacharjee and Das 2002). Since withdrawing the variables reduces the explanatory power of the model, an AFT model was used as in Lavado and Gallegos (2005) although with a Weibull distribution. This distribution was selected because the risk of drop-out was found to be monotonically increasing.

The other advantage of using AFT models is that they provide a way to make sequential estimations, based on a density function that is built from empirical information without the need to eliminate it (Lavado and Gallegos 2005). When one has a reason to believe that the hazard function follows a certain shape, imposing a hazard function improves the efficiency of the estimates (Cleves et al. 2004).

To incorporate the effects of the time-varying nature of the economic shock variables, the data were split at each time period (t) using the stsplit command of Stata, which automatically fills in the time and failure of variables appropriately (Cleves et al. 2004). The economic shock variables were interacted with the time variable and included in the regression to capture the effect of time.

The estimation of equation (1) was made for the number of children dropping out of primary school conditional upon the child's current enrolment to primary school. The dependent variable is generated from the highest grade the children have reached. The children who are attending school are censored in contrast to the children who are not being enrolled in school in Round 3. Our failure cases for the Weibull regression are, therefore, the uncensored observations, i.e., the children who are not attending school. Eighteen percent of the children in the sample have completed primary education. These children are considered as those that have survived throughout primary school regardless of being subjected to the effects of economic shocks.

In addition to the estimation of the full model with the data from the full sample, several regressions were run to check for the robustness of the results and the relative importance of the 
determinants for different groups. To evaluate whether the direction of relationships change and the extent to which the statistical significance of the estimated coefficients change with different specifications, two models in which the economic shocks of each round (round 2 and round 3) are incorporated separately were estimated. In addition, the full model was estimated using disaggregated data based on the location of households (rural/urban) and gender of the child, to explore the relative importance of those determinants in the risk of children dropping out of primary school.

\section{Results and Discussion}

As was discussed in Section 3, an AFT model with Weibull distribution is adopted to investigate the impact of economic shocks on the risk of children dropping out of primary school. Please note that children who are attending school are censored in contrast to the children who are not being enrolled in school in Round 3. Our failure cases for the Weibull regression are, therefore, the uncensored observations, i.e., the children who are not attending school. The dependent variable is therefore the number of years of schooling conditional upon the current enrolment of children in primary school, which is indirectly a dropout model with censoring.

In the following sub-sections, the results of the various Weibull regressions are discussed. In addition to the results from the full model, the results of the estimations made by incorporating economic shocks from Round 2 and Round 3 separately are discussed to see how the results change with differences in the specification of the model. The results of the Weibull estimation using data disaggregated by location of household and gender of the child are also discussed.

\subsection{Full model}

The results of the AFT model with a Weibull distribution showed that none of the household and child characteristics variables were found to have a statistically significant effect on the probability of children dropping out of school. However, all of the economic shock variables of Round 2 were found to have a statistically significant impact on the probability of children dropping out of school. Similarly, the interaction of dummy variables of economic shocks in 
Round 2 and time were found to have a statistically significant relationship with the chances of children dropping out of school. Moreover, the variables that accounted for the number of hours that the children spent on different activities were found to have a statistically significant effect. Household wealth and the age the children started school were also found to have a statistically significant effect.

Controlling for other factors including economic shocks, the age the children started school was found to have a statistically significant effect on the probability of children completing primary school. A unit increase in the age of a child when he/she started school was found to reduce the chance of a child completing school by $9.6 \%$ per cent. This indicates that the further a child's enrolment in school is delayed, the higher the chances are of the child not finishing primary school.

Among the economic shocks incorporated in this model, all of the ones experienced in Round 2 were found to have a statistically significant effect on the chances of children dropping out of school. Households' experience of death or illness of a member in Round 2 was found to have negative effect on the probability of a child staying in school. A child from a household that has faced such a shock is 27.6 per cent less likely to complete primary school than a child whose household didn't have its members die and/or get ill. This result is expected as children may need to drop out of school to raise income after the death of a breadwinner. The illness of household members may also cause the probability of drop-out to be more likely as children are required to spend more time at home looking after the ill household member or substituting for the labour requirements of that household member.

Children whose households experienced drought, crop failure, pests and/or diseases in Round 2 were also more likely to have dropped out of primary school. A child from a household that had experienced these shocks was found to be less likely to complete primary education by 32.2 per cent than a child whose household had not experienced any such shocks. This indicates that the drought and crop failure affect completion by reducing households' economic situation and reducing households' ability to cope up with these economic shocks. 
On the other hand, children who come from a household that experienced death of livestock in Round 2 were found to have a higher likelihood of staying in primary school than children whose households did not have their livestock die. A child from a household that experienced the death of livestock was found to be 54.8 per cent more likely to complete primary education than the children whose households did not experience such a shock. This may look counter-intuitive at a first glance. However, there is a plausible explanation for this result. The death of livestock leads to a reduction in the number of cattle that children are expected to herd, leading to a reduction in the time the child spends on cattle-keeping, and allows for more time to be allocated to school, hence there is a higher probability of the child spending time at school.

To account for the time-varying nature of the shock variables, each of the shock variables was interacted with time and included in the regression as additional covariates. The results showed that two of the interaction variables had a statistically significant effect on the probability of a child dropping out of school. If the household the child is from has experienced drought, crop failure, or pest infestations and diseases, the probability of the child staying in school increases by 8.7 per cent. On the other hand, a unit increase in the time reduces the probability of a child staying in school by 7 per cent if the household the child is from has had livestock die indicating that when death of livestock now will increase dropout in the future. This means death of livestock reduces dropout in the short run because of the direct effect on the demand for labour and increases dropout because deteriorating economic condition.

In contrast, none of the economic shocks that households experienced in Round 3 were found to have a significant relationship with the probability of children completing primary school. This may be an indication that economic shocks take a certain amount of time before they affect children's completion of primary education. 
Child and household characteristics

Dummy for boy

Coefficient

Dummy for male-headed household

$-0.097$

$(-1.49)$

0.044

$(0.69)$

Dummy for literate father

0.001

$(0.03)$

Dummy for attending preschool

$-0.073$

$(-0.86)$

Dummy for urban households

0.134

(1.63)

Age of starting school

$-0.096 * * *$

$(-5.39)$

Number of boys aged 7 years or below

$-0.025$

$(-0.66)$

Number of boys between the age of 7 and 17

0.026

$(0.91)$

0.001

Number of male family members between the age of 17 and 65

Number of male family members aged 65 years or more

$-0.046$

$(-0.66)$

Number girls less than or equal to 7 years old

$-0.038$

$(-1.15)$

Number of girls between the age of 7 and 17

$-0.019$

$(-0.69)$

Number of female family members between the age of 17 and 65

$-0.031$

$(-1.47)$

Number of female family members aged 65 years or more

$-0.037$

$(-0.5)$

Wealth

$0.376^{*}$

\section{Child's time allocation}

Hours spent per typical day on domestic activities

$-0.114 * * *$

$(-6.46)$

Hours spent per typical day on unpaid activities

$-0.117 * * *$

$(-7.28)$

Hours spent per typical day on paid labour

$-0.105 * * *$

$(-7.6)$

Shocks in Round 3

$-0.096$

$(-0.69)$

Dummy for death of livestock 
Dummy for drought, crop failure, pests and diseases

\section{Shocks in Round 2}

Dummy for death or illness of household members

$-0.276^{* *}$

$(-2.08)$

Dummy for death of livestock

$0.549 * * *$

Dummy for drought, crop failure, pests and diseases

$-0.321 * *$

$(-2.05)$

\section{Economic shocks interacted with time}

Interaction dummy for death or illness of household members in Round 2 and time

Interaction dummy for death of livestock in Round 2 and time

Interaction dummy for drought, crop failure, pests and diseases in Round 2 and time

Interaction dummy for death or illness of household members in Round 3 and time

Interaction dummy for death of livestock in Round 3 and time

Interaction dummy for drought, crop failure, pests and diseases in Round 3 and time

Constant

$\ln \_p$

$\mathrm{P}$

Source: Own computation based on Young Lives Older Cohort data.

\subsection{Classification based on location and gender}

With the aim of identifying the determinants of drop-out, similar Weibull regressions were run using the disaggregated data based on the location of the household (rural/ urban) and the gender of the child. We first conducted log rank tests for the equality of survivor function for boys and girls and for rural and urban children. Under the null hypothesis that the survival functions of boys and girls is the same and for rural and urban children is the same, the test statistics have a Chi- 
squared distribution with one degree of freedom. The test result suggested that we reject the null hypothesis at 5 per cent indicating the survival functions of boys and girls are not the same. Similarly we reject the null hypothesis that the survival function for rural and urban children is the same at 1 per cent, indicating the survival functions of rural and urban children are not the same. Therefore, we estimated separate AFT model using Weibull regressions for boys and girls and for rural and urban children.

Most of the results were found to be statistically insignificant as disaggregating the data further reduces the number of observations. However, the results provide some insight into how the various factors under consideration affect children living in rural areas relative to those living in urban areas, and girls relative to boys as opportunity cost of children education is different for boys and girls and for rural and urban children. Moreover, credit constraints which is one of the reasons for children's involvement in work instead education that has long-term benefits (Glewwe and Jacoby, 1984).

\subsubsection{Classification based on location}

The significance of the economic shock variables differed based on the location of the households. Households' experience of drought, crop failure, pests and/or diseases in Round 2 was found to have a negative and statistically significant effect on the probability of a child completing primary school in rural areas. Similar to the case in the full model, children from a household that has had livestock die in the rural areas were found to have a higher probability of completing primary school than the children who did not. Consistent with the arguments of Sun and Yao (2010, one of the economic shocks namely, the death or illness of a household member, was found to have a negative effect on the probability of completing primary school in both the rural and urban areas.

In addition, the effects of children's time allocation to domestic activities, unpaid activities and paid labour were all found to have a statistically significant effect on the risk of children dropping out of school regardless of the location of the household. An increase in the number of hours spent on each of these categories of activity was found to have a declining effect on the likelihood of a child completing primary school. These results supports the theoretical argument by Glewwee and 
Jacoby, 1984 that the opportunity cost of sending to school prevents households from sending their children to school.

\subsubsection{Classification based on gender of child}

Although the death or illness of household members did not have a statistically significant effect on the probability of children completing primary school, for either boys or girls, both households' experience of the death of cattle and their experience of crop failure were found to have a statistically significant effect on the probability of boys and girls dropping out of school. Boys and girls from a household that has experienced drought, crop failure, pests and/or diseases were found to be less likely to complete primary education than children from households that have not. The probability of completing primary school was more negatively affected for girls (40.3 per cent) than for boys (31.9 per cent) whose households have faced such a spell.

Similar to the case of the full model and the disaggregated regressions, the death of livestock was found to have a positive relationship with the probability of completing primary school for both boys and girls. The effect was bigger for boys ( 49.2 per cent) than for girls (38.9 per cent). This could be because boys are mostly the ones sent out for cattle keeping than girls.

\subsection{Estimation results from models incorporating economic shocks in different survey rounds}

To check for the robustness of the results of the initial regression, two other models were regressed which incorporate the economic shock variables of Round 2 and Round 3, separately. The statistical significance and the direction of relationship of the variables with the risk of dropping out of school remained the same in both models, although the extents of the effects were found to be different.

In the regression of the model that contains shock variables from Round 2 only, all of the economic shock variables were found to have a statistically significant relationship with the probability of completing primary school. In the model that contains shock variables from Round 3 only, the death or illness or of household members was found to have a statistically significant effect on the 
probability that the child completes primary school. It is only in this regression that a shock from Round 3 is found to have a statistically significant effect on the likelihood of children completing primary school confirming once again that shocks via their effect on asset accumulation and households' economic conditions affect child education completion (Sun and Yao, 2010).

\subsection{Discussion on the implication the results for social policy}

Constitutional rights, policies and programs in Ethiopia strongly support and promote the equitable inclusion vulnerable groups lagging behind in access to quality education which helps children to complete primary education (MoE, 2008). As an attempt to fulfil this commitment, the Ethiopian government allocates the highest share to education sector, up to $28 \%$ of the budget. However, with increasing number of children in school, the budget allocated for the education sector is not sufficient enough to provide necessary support for poor children suffered by work burden and hunger mainly coming from economic shocks facing parents such as death and illness of family members, death of livestock, drought and crop failures.

In a situation where government is highly constrained to support poor children in and out of school, it is important to link primary education to social protection by recognizing the shocks that affect households' ability to send their children to school. Social protection could help households cope with the various kinds of shock. In addition, providing households with incentives to make their children attend school instead of having them spend their time on paid and unpaid work would also contribute to a reduction in the probability of children dropping out primary school. This could be done by introducing a cash transfer programme conditional on children's attendance at school or reshaping the existing social protection programme, the PSNP, so as to incorporate a cash transfer component conditional on school attendance.

A good model for this is Progresa, which is a conditional cash transfer program operating in Mexico as discussed by De Janvry et al. (2006). According to De Janvry et al. (2006), children whose families are recipients of conditional transfers are insulated from the impacts of shocks on school enrolment and work. The results of the study showed that conditional cash transfer programmes contributed positively to the protection of children's enrolment in school, which 
indicates that conditional cash transfer programmes can act as safety nets that enable poor children to attend school. 
Table 2. Estimation results from models with economic shocks of separate rounds

\begin{tabular}{llll}
\hline & \multicolumn{3}{c}{ Coefficient } \\
\cline { 2 - 3 } & Round & 2 & Round \\
shocks & shocks & 3 \\
\hline
\end{tabular}

Child and household characteristics

Dummy for male-headed household

$0.051 \quad 0.03$

$(0.74) \quad 0.4$

Dummy for literate father

$0.006-0.026$

(0.11) $\quad-0.49$

Dummy for attending preschool

$-0.084 \quad 0.008$

Age of starting school

$(-0.94) \quad 0.08$

Number of boys aged 7 years or below

$-0.109 * * * \quad-0.110 * * *$

$(-5.8) \quad-5.4$

$-0.034 \quad-0.022$

$(-0.82) \quad-0.51$

Number of boys between the age 7 and 17

$0.015 \quad 0.031$

$(0.54) \quad 1.03$

Number of male family members between the age of 17 and 65

0.004

0.008

$(0.16) \quad 0.34$

Number of male family members aged 65 years and more

$-0.093$

$-0.123$

$(-1.26)$

$-1.57$

Number girls less than or equal to 7 years old

$-0.046$

$-0.044$

$(-1.25)$

$-1.16$

Number of girls between age 7 and 17

$-0.006$

0.015

$(-0.2)$

0.48

Number of female family members between the age of 17 and 65

$-0.026$

$-0.027$

$(-1.12)$

$-1.1$

Number of female family members aged 65 years or older

$-0.022$

$(-0.27)$

$0.434 * *$

$-0.042$

$-0.5$

Wealth index

(2.21)

$0.389 * * *$

1.88

Child's time allocation

$-0.121 * * * \quad-0.119 * * *$

Hours spent per typical day on domestic activities

$(-6.62) \quad-6.21$

Hours spent per typical day on unpaid activities

$-0.137 * * * \quad-0.127 * * *$

$(-8.05) \quad-7.01$

Hours spent per typical day on paid labour

$-0.117 * * *$

$(-7.86)$

$-0.114 * * *$

Shocks in Round 2

Dummy for death or illness of household members

$-0.315^{* *}$

$(-2.25)$

Dummy for death of livestock

$0.607 * * *$

(3.26)

Dummy for drought, crop failure, pests and diseases

$-0.393 * *$ 


\section{Shocks in Round 3}

Dummy for death or illness of household members

$-0.286^{*}$

Dummy for death of livestock

$-0.201$

Dummy for drought, crop failure, pests and diseases

Economic shocks interacted with time

Interaction dummy for death or illness of household members in Round 2 and time

Interaction dummy for death of livestock in Round 2 and time

Interaction dummy for drought, crop failure, pests and diseases in Round 2 and time

Interaction dummy for death or illness of household members in Round 3 and time

Interaction dummy for drought, crop failure, pests and diseases in Round 3 and time

Constant

Source: Own computation based on Young Lives Older Cohort data.

\section{Summary, conclusion and recommendation}

The results of the regression showed that children who belong to a household that experienced the death or illness of a household member in Round 2 faced more risk of dropping out of primary school in Round 3, compared to children whose households did not face such shocks. The results 
also show that the same shock has a statistically significant effect on the risk of children from urban households and on girls dropping out of school.

Furthermore, children from a household that has experienced death of livestock were found to face less risk of dropping out primary school than children who belong to households that have not faced the death of livestock. Death of livestock allows children to allocate more time to school and, therefore reduces their chance of dropping out of school. This result remained the same in the alternative estimations as well. Moreover, the separate estimations made for boys and girls and for rural and urban children showed that this economic shock has a statistically significant effect on the risk of children dropping out of primary school in the rural areas and among boys.

The fact that these shocks are experienced at the household level shows that social assistance programmes should include not only covariate shocks but also idiosyncratic shocks, which households experience on their own, if the desired result is to strengthen the country's accumulation of human capital. Moreover, it is important to link primary education to social protection by recognizing the shocks that affect households' ability to send their children to school.

Learning from the experiences of Latin America, Social protection should help households cope with the various kinds of shock. In addition, providing households with incentives to make their children attend school instead of having them spend their time on paid and unpaid work would also contribute to a reduction in the probability of children dropping out primary school. This could be done by introducing a cash transfer programme conditional on children's attendance at school or reshaping the existing social protection programme, the PSNP, so as to incorporate a cash transfer component conditional on school attendance.

In this regard, reducing school dropout rates and improving primary education completion rates is not just a question of changing education policy, but also of addressing other social and economic issues and hence these questions should concern not only that the Ministry of Education, but also policymakers and officials in other sectors. 


\section{Reference}

Admassu, K. A. 2011 'Primary school enrolment and dropout in Ethiopia: Household and school factors', paper presented to the Population Association of America, Annual Meeting Program, 31 March - 1 April 2011, Washington DC

Asadullah, M. N., Chaudhury, N. and Christiaensen, L. 2006. Schools, household risk and gender: Determinants of child schooling in Ethiopia, CSAE Working Paper 2006-6, Oxford: Centre for the Study of African Economies, University of Oxford

Bijorkman, Martina 2005. Income shocks and gender gaps in education: Evidence from Uganda, Seminar Paper No. 744, Stockholm: Institute for International Economic Studies, Stockholm University

Bhattacharjee, A. and Das, S. 2002. Testing proportionality in duration models with respect to continuous covariates, Cambridge Working Paper in Economics No. 220, Cambridge: University of Cambridge

Bratti, M. and Mendola, M. 2011. Parental health and child schooling, IZA Discussion Paper No. 5870, Bonn, Institute for the Study of Labor (IZA)

Brown, Philip H. and Park, A. 2002 Education and poverty in rural China, Economics of Education Review 21.6: 523-41

Cleves, M. A., Gould, W.W. and Gutierrez, R.G. 2004. An introduction to survival analysis using Stata (revised edition), College Station, TA: Stata Press

Cox, D.R. 'Regression models on life - Tables (with discussion)' in Cleves, M.A., Gould W.W. and Gutierrez, R.W. 2004. An introduction to survival analysis using Stata (revised edition), College Station, TA: Stata Press

Cox, D.R. and Oakes, D. 1984. Analysis of survival data, London: Chapman and Hall de Janvry, A., Finan,F., Sadoulet, E. and Vakis, R. 2006. Can conditional cash transfer programmes serve as safety nets in keeping children at school and from working when exposed to shocks?, Journal of Development Economics 79: 349-73

Dureyea, S. 1998. Children's advancement through school in Brazil: The role of transitory shocks to household income, Working Paper No. 376, Washington DC: Inter-American Development Bank 
Gingoux, J. and Mendez, M. 2011 Critical Periods and the long-run effects of income shocks on education: Evidence from Indonesia, paper presented to the Développement, Institutions et Mondialisation (DIAL) Development Conference, 30 June - 1 July 2011, Paris

Glewwe, P. and Jacoby, H. 1994 Student achievement and schooling choice in low-income countries: Evidence from Ghana', Journal of Human Resources, 29.3: 843-64

Glewwe, P., Grosh, M., Jacoby, H. and Lockheed, M. 1995 An eclectic approach to estimating the determinants of achievement in Jamaican primary education, Oxford Journals 9.2: $231-58$

Glick, P.J., Sahn, D.E., and Walker, T.F. 2011. Household shocks and education investment in Madagascar, Working Paper No. 240, New York, NY: Cornell Food and Nutrition Policy Program, Cornell University

Gunnarson, V., Orazem, P.F. and Sanchez, M.A. 2004. Child labor and school achievement in Latin America, The World Bank Economic Review 20.1: 31-54

Handa, S. and Simler, K.R. 2000. Quality or Quantity? The supply-side determinants of primary schooling in rural Mozambique, FCND Discussion Paper No. 83, Washington, DC: International Food Policy Research Institute

Holmes, J. 2003. Measuring the determinants of school completion in Pakistan: Analysis of censoring and selection bias, Economics of Education Review 22.3: 249-64

Hunter, N. and May, J. 2002. Poverty, shocks and school disruptions: Episodes among adolescents in South Africa, CSDS Working Paper No.35, Durban: School of Development Studies, University of NatalKim, Namsuk and Martha Serra-Garcia (2010) Economic Crises, Health and Education in Jamaica, UNDP/ODS Working Paper, New York: United Nations Development Programme

Krutikova, S. 2010. Who gets to stay in school? Long-run impact of income shocks on schooling in rural Tanzania, CSAE Working Paper 2010-36, Oxford: Centre for the Study of African Economies, University of Oxford

Lavado, P. and Jose, G. 2005. The dynamics of the schooling drop-out in Peru: A framework using duration models, Lima: Centro de Investigacion de la Universidad del Pacifico

Lincove, J. A. (2009) 'Determinants of schooling for boys and girls in Nigeria under a policy of Free Primary Education', Economics of Education Review 28.4: 474-84 
MoE 2008. General Education Quality Improvement Package (GEQIP). Ministry of Education (MoE), Addis Ababa, Ethiopia. November 2008.

MOE 2011. Education Statistics Annual Abstract 2003 E.C. / 2011-12 G.C., Addis Ababa: Ministry of Education

MoE 2013. Social Assessment of GEQIP Phase 2 Ethiopia. Ministry of Education (MoE), July 2013. Addis Ababa, Ethiopia.

MOFED 2008. Dynamics of growth and poverty in Ethiopia: 1995/96-2004/05, Addis Ababa: Ministry of Finance and Economic Development

Sun, A. and Yao, Y. 2010. Health shocks and children's school attainments in rural China, Economics of Education Review 29.3: 375-82

Tafere, Y. and Woldehanna, T. 2012. Beyond food security: Transforming the productive safety net programme in Ethiopia for the well-being of children. Working Paper no. 83. Oxford Department of International Development (ODID), University of Oxford, Queen Elizabeth House,3 Mansfield Road, Oxford OX1 3TB, UK

Woldehanna, T., Jones, N. and Tefera, B. 2005. Children's educational completion rates and achievement: implications for Ethiopia's second poverty reduction strategy (2006-10), Young Lives Working Paper 18, Oxford: Young Lives

World Bank 2004. Buildings, and learning outcomes: An impact evaluation of world bank support to basic education in Ghana, Report No. 28779, Washington, DC: World Bank United Nations 2011. The Millennium Development Goals Report, New York, NY: United Nations 